\title{
Discourse Analysis on Campus News in University Image Construction
}

\author{
Haijian Dan and Xiaoben Yin* \\ School of Foreign Language, Wuhan University of Technology, Wuhan, China \\ * Corresponding author Email: 1043615478@qq.com
}

\begin{abstract}
Campus news is one of the most important aspects of the university image construction. This paper takes campus news of Wuhan University of Technology, Seoul National University, Harvard University as corpus, and applies systemic-functional grammar to analyze the transitivity, the subjectivity of the news headlines, and modal verbs of campus news of three universities and explain cultural causes of it. The paper finds that Wuhan University of Technology has constructed an authoritative image in the construction process, and the power has a great influence on the news. The influence of power in campus news of Harvard University is relatively small. The power influences the news of Seoul National University a lot. The findings of this paper are expected to provide practical suggestions for the expression of campus news and image construction of Chinese universities.
\end{abstract}

Keywords: Campus news, University image construction, Systemic-functional grammar, Power.

\section{INTRODUCTION}

Image construction is an effective method to improve the fame and reputation of social organizations, and enhance the internal cohesion of organizations and their social competitiveness (Li Yihua, Yan Yanbin, 2002:89-92). With the development of new media, universities put campus news on the official website, which is an important way to construct the image of universities today. In the age of information, official website of the university is the main bridge connecting the university and the society. The public can see the basic appearance of a university through it and form the basic impression of the university. It is of great significance to construct the official website of the university and construct a good image of the university to enhance the social influence of the university.

To improve the internationalization level of Chinese universities, this paper will explore the cultural causes of the image construction differences and similarities among the three universities. For the convenience of research, we take Seoul National University, which is also influenced by oriental culture but has a higher international reputation, as an intermediate reference, and make a comparative study of the campus news of the three universities.
Based on systemic-functional grammar and guided by critical discourse analysis, this paper analyzes the similarities and differences of the three universities' news from the aspects of transitivity, subjectivity and modality in the process of constructing the university image. The task of this paper is to find out the influence of power of those three universities by applying the critical discourse analysis.

\section{THEORETICAL FRAMEWORK}

Critical discourse analysis (CDA) should deal primarily with the discourse dimensions of power abuse and the injustice and inequality that result from it (Halliday, 2012:6-11). Critical discourse analysis aims to analyze the relationship between language, power and ideology, and to reveal how texts originate from and serve social structure and power relations (Xin Bin, Gao Xiaoli, 2013:1-5).

For the policy text, Elin Margrethe Aasen and Berit Misund Dahl adopt Fairclough's critical discourse analysis to analyze the text of the Patients' and Service Users' Rights Act and comments. The study finds that patients have a relatively weak image and lack of power in these comments. For the construction of university image, Peter Teo, based on the theoretical principles of critical discourse analysis, analyzes the information of 
university presidents on the websites of 36 top universities in China. He believes that Chinese universities must remain loyal to the political ideology and national interests which China's top universities must process. However, he only analyzes the the presidents' information which is not comprehensive.

There are three main methods of critical discourse analysis: systemic-functional grammar analysis, interweaving analysis of discourse and genre and historical background analysis of discourse (Halliday, 2011:138-46). Systemic functional grammar has been widely applied in the image construction in news. Huang Lou uses systemic functional grammar and the comparative method to study the differences and similarities of opinions and positions of headlines and high-frequency words of headlines and modifiers of key words, and explores the discourse construction status of Dongguan city image. To construct a more positive image of the city, it provides good suggestions. Therefore, this paper will analyze the similarities and differences in the construction process of the three universities by using systemic functional grammar.

Systemic-functional grammar was founded by British linguist Halliday in the late 1950s. Systemic-functional grammar studies the nature of language, process of language and other fundamental language issues, and discusses the application of linguistics. Halliday holds the belief that language has three basic functions: ideational metafunction, interpersonal metafunction and textual metafunction. Ideational metafunction refers to the categories of experience of real world. It is realized by transitivity. Interpersonal metafunction refers to the function to express the modality of speakers towards the people and subjects, which is realized by mood and modality. Textual metafunction refers to the style of discourse organization, and it is realized by thematic structure.

\section{RESEARCH PROCESS}

This paper collects the campus news of Wuhan University of Technology, Seoul National University and Harvard university from December 2015 to March 2020. The number of the news of Wuhan University of Technology is 2003. Harvard University is 1213, and Seoul National University is 509. Through stratified sampling, 200 pieces of news from Harvard University, 100 pieces of news from Seoul University and 50 pieces of news from Wuhan University of Technology were selected as the corpus for analysis.

\subsection{Transitivity}

Halliday believes that transitivity consists of six processes: material process, mental process relational process, verbal process, behavioral process and existential process. Material process refers to the process of "doing something", such as "agree","expand”,"apply”and“accuse”.

Mental process is a process expressing such mental phenomena as "perception", "reaction" and "cognition", such as "hope", "consider" and "want". Relational process indicates a relationship or property between one object and another, such as "would be" and "is". Verbal process is that of exchange information. Commonly used verbs are: "said", "claim" and "told". Behavioral process refers to physiological and psychological behavior such as "laugh", "listen" and "see". Existential process represents that something exists or happens, such as "there be". This paper analyzes the ratio of these six processes in the news of Wuhan University of Technology, Seoul National University and Harvard University.

Material process describes the process by which the events develop, realized by substantive verbs. In news discourse, in news discourse, the greater the proportion of material process, the more respect the reality of news, the more emphasis on the objectivity of news. The material process of Harvard University news accounts for $59 \%$. Seoul National University is $60 \%$. Wuhan University of Technology is $56 \%$ which accounts for the most. It indicates that the news of three universities all emphasize the fact in their campus news.

Mental process is a process which expresses the subjective opinion, but the news emphasizes the objectivity and truth. Therefore, mental process is less used in the news discourses. The proportion of the three universities in this process is relatively small. Harvard University has 3\%. Seoul National University is $9 \%$, and Wuhan University of Technology is 5\%. It is consistent with the characteristics of news discourse. But Seoul National University has higher proportion of mental process than other two universities, which indicates that it adds more subjective opinions in its campus news than other two universities. 
Table 1. The analysis of transitivity

\begin{tabular}{|c|c|c|c|c|c|c|}
\hline & $\begin{array}{c}\text { Material } \\
\text { process }\end{array}$ & $\begin{array}{c}\text { Mental } \\
\text { process }\end{array}$ & $\begin{array}{c}\text { Relational } \\
\text { process }\end{array}$ & $\begin{array}{c}\text { Behavioral } \\
\text { process }\end{array}$ & $\begin{array}{c}\text { Verbal } \\
\text { process }\end{array}$ & Existential process \\
\hline $\begin{array}{c}\text { Harvard } \\
\text { University }\end{array}$ & $59 \%$ & $3 \%$ & $12 \%$ & 0 & $24 \%$ & $2 \%$ \\
\hline $\begin{array}{c}\text { Seoul National } \\
\text { University }\end{array}$ & $60 \%$ & $9 \%$ & $23 \%$ & 0 & $6 \%$ & $2 \%$ \\
\hline $\begin{array}{c}\text { Wuhan } \\
\text { University of } \\
\text { Technology }\end{array}$ & $56 \%$ & $5 \%$ & $11 \%$ & 0 & $28 \%$ & 0 \\
\hline
\end{tabular}

Relational process mainly reflects the relationship among various subjects in news and put emphasis on the description of significance of them. Therefore, the relational process is frequently used to present the relationship and mutual situation between characters in the news. In this process, Harvard University has $12 \%$. Seoul National University reaches up to $23 \%$, and Wuhan University of Technology is $11 \%$. Compared with other two universities, Seoul National University emphasize the significance of news events and relationships and situations of characters.

Speech process refers to the process of exchanging information through speech. Generally, the speech of parties and authorities will be quoted in the news reports to increase the credibility and authority. In this process, Wuhan University of Technology has 28\%. Harvard University is $24 \%$, but Seoul National University only has $6 \%$. Wuhan University of Technology put much emphasis on the credibility and authority of its campus news, constructing an authoritative image, and Harvard also makes such image. Nevertheless, the proportion of Seoul National University of this process is much lower than other two universities, but relational process has $23 \%$. It is totally unbalanced.

Existence process is a static process that represents the meaning of objective existence, but description of dynamic events is the main characteristic of news report. So the proportions of three universities are relatively small, and they are separately $2 \%, 2 \%$ and 0 .

\subsection{The Subjectivity of News Headlines}

News headlines usually express the news contents, perspectives, positions and ideology succinctly, which has become the important part of news discourse researches. We classify the categories of the subjects of those three universities' news headlines: they are leader, advanced individual, collective and others. The following is the proportion of different subjects in the headlines of campus news of the three universities:

The subjects of headlines of campus news of three universities are very different. The leader subjects of Harvard campus news headlines account for $10 \%$. What's more, most leader subjects are presidents. 36\% are advanced individuals. Collective account for $42.5 \%$, and $11.5 \%$ are others. In the campus news headlines of Seoul National University, leader subjects account for $23 \%$. Subjects of advanced individuals account for $40 \%$. $27 \%$ are collective subjects, and others account for $10 \%$. In the campus news headlines of Wuhan University of Technology, the leader subjects account for $48 \%$. Advanced individual subjects are $32 \%$. Collective subjects only account for $4 \%$, and others are $16 \%$. The subject of headlines shows different emphasis of three universities. Harvard University emphasizes the influence of decision-making body on school decisions. Wuhan University of Technology and Seoul National University emphasize the influence of leaders or advanced individuals, so the subject of the title is the specific leader or person.

The differences of subjects reflect the different degree of power control in three universities, and there are different cultural causes behind them.

\subsection{Modality}

Modality can reflect the speaker's attitude towards proposition, which mainly includes two kinds: one is the cognitive attitude to express truth, belief, possibility and certainty. The second is to express the desirability, preference, intention and manipulation of evaluative attitude. In news discourses, the author usually uses the modal verbs to convey the implied information. The frequency of using modal verbs of three universities is as followed: 
Table 2. The analysis of subjects of news headlines

\begin{tabular}{|c|c|c|c|c|}
\hline & Leader & Advanced individual & $\begin{array}{c}\text { Collective(school } \\
\text { board, student union) }\end{array}$ & Others \\
\hline Harvard University & $10 \%$ & $36 \%$ & $42.5 \%$ & $11.5 \%$ \\
\hline $\begin{array}{c}\text { Seoul National } \\
\text { University }\end{array}$ & $23 \%$ & $40 \%$ & $27 \%$ & $10 \%$ \\
\hline $\begin{array}{c}\text { Wuhan University of } \\
\text { Technology }\end{array}$ & $48 \%$ & $32 \%$ & $4 \%$ & $16 \%$ \\
\hline
\end{tabular}

Modal verbs "will" can express an objective mood. Harvard University uses "will" 816 times in 200 pieces of news, which indicates that Harvard University wants to convey objective and truthful information to the readers. Seoul National University uses "will" 144 times in 100 pieces, and Wuhan University of Technology uses 41 times in 50 pieces. "can" and "should" will convey a strong mood that means an order. Harvard University uses "can" 224 times in 200 pieces of news. Seoul National University uses "can" 224 times and "should" 15 times in 100 pieces. Wuhan University of Technology uses "can" 12 times and "should" 19 time in 50 pieces. The frequency of using "should" is much higher than those of other two universities, which suggests that the mood of campus news of Wuhan University of Technology is much stronger than other two universities.

\subsection{Cause Analysis}

From the analysis of part 3, we can see that there are differences and similarities among the three universities' news.

For the news of Wuhan University of Technology, we can see that it uses more material processes, and fewer mental processes in their campus news by analyzing the transitivity of news, which indicates that the news of it is objective and truthful. However, for the subjectivity of news headlines, leader subjects of news headlines reach up to $48 \%$, which is much higher than other two universities. What's, several subjects are government officials. While the collective subjects only account for 4\%. What's more, it uses "should" 19 times in order to convey a strong mood. It can be seen that the campus image construction of Wuhan University of Technology is greatly influenced by power.

For the news of Harvard University, we find that Harvard University also pay attention to the authority, authenticity and objectivity of campus news by analyzing the transitivity of the news discourse. For the subjectivity of campus news headlines, leader subjects only account for $10 \%$, and usually the subjects are usually the presidents of Harvard University. Collective subjects account for $42.5 \%$, and for the modality, the
Harvard university use "can" and "should" less. So the campus image construction of Harvard University is less influenced by the power.

Seoul National University is a university influenced by oriental culture, but there are opposite characteristics in several places compared with Wuhan University of Technology. American culture has also exerted a profound influence on Korean culture since modern times. Therefore, there are several statistical similarities with Harvard University, for example, in the use of modal verbs, they use fewer modal verbs which express strong moods. Seoul University news only uses "should" 4 times, and the mood of news statements is gentler.

\section{CONCLUSION}

Firstly, Wuhan University of Technology constructs an objective, authentic and authoritative university image in the process of image construction in campus news. Nevertheless, as Chinese universities have to assume certain political functions to a certain extent, power has a great influence on campus news discourses, but advanced individuals account for a large proportion. It also shows that Wuhan University of Technology also attaches great importance to scientific research and academy, which is consistent with its educational philosophy "academic supremacy and educational orientation".

Secondly, the campus news of Harvard University also conforms to the authenticity and objectivity principle of news discourses. At the same time, it constructs an authoritative and objective university image. From the analysis of transitivity of Harvard news and characteristics of subjects of news headlines, the power has little impact on its news discourse.

Thirdly, Seoul National University has been influenced by the western culture since modern times, and tried to learn from western universities. But it does not construct an authoritative and objective university image in the process of its university image construction, and authority is also affected. The power has great influence on its campus news. 


\section{AUTHORS' CONTRIBUTIONS}

Professor Dan selects a topic and provides overall ideas. And also he makes great efforts to revise the paper. Finally he agrees me to submit this paper to this conference. I design the paper framework, collect the references and all the corpus and analyze the corpus to get the data. And at last I complete this paper.

\section{ACKNOWLEDGMENTS}

First of all, I will thank my supervisor Haijian Dan. Mr. Dan helped me a lot in the selection, construction and later revision of the thesis. In writing the paper, Mr. Dan is a good teacher, as a teacher, he gave me a lot of advice. Without his inculcation and patient guidance, my paper would not have been completed so smoothly. Here, I express my most sincere thanks to $\mathrm{Mr}$. Dan. Secondly, I would like to thank my dear friends. In the process of writing the paper, they encouraged me again and again, and let me keep on with the courage when I am distressed by the paper. Finally, I want to thank my parents for their best support. They are my strongest backing.

\section{REFERENCES}

[1] Aasen E M, Dahl B M. Construction of patients' position in Norway's Patients' Rights Act [J]. Nursing Ethics, 2018.

[2] Fairclough N (1989) Language and Power [M]. New York: Longman.

[3] Fowler, B. Hodge, G. Kress \& T. Trew (eds.).Language and Control [C]. London: Routledge \& Keegan Paul.185-213.

[4] Teo P, Ren S. Marketization of universities in China: A critical discourse analysis of the university president's message [J]. Discourse \& Communication, 2019(2):175

[5] Pascual, Pérez-Paredes, Pilar, et al. Constructing immigrants in UK legislation and Administration informative texts: A corpus-driven study (2007-2011)[J]. Discourse \& Society, 2017.

[6] Halliday. 2011. Text, discourse, information -From the perspective of Systemic-functional Linguistics [J]. Journal of Beijing University (Philosophy and Social Sciences edition) 28(1):138-46.

[7] Li Yihua, Yan Yanbin. An Analysis of the Image Construction of Colleges and Universities [J]. Modern University Education 2002(2):89-92. 